\title{
Narrativas Emocionais de Estudantes do Ensino Superior em Tempos de Quarentena
}

\author{
Emotional Narratives of Higher Education Students in \\ Quarantine Times
}

\author{
Catarina Sobral * \\ Ana Paula Caetano
}

Universidade de Lisboa, Portugal

\begin{abstract}
As épocas de crise são períodos complexos onde coexistem dinâmicas que acentuam as dificuldades, mas também que criam oportunidades de superação individual e coletiva, no sentido de uma maior equidade e inclusão social. Com a pandemia do Covid-19, foram introduzidas mudanças nas nossas vidas. Em Portugal as universidades fecharam e substituíram as aulas presenciais do $2^{\circ}$ semestre por aulas virtuais síncronas e assíncronas. Situação que inicialmente se pensava transitória, mas manteve-se até ao final do ano letivo 2019/20. Enquanto professoras de um grupo de estudantes do $2^{\circ}$ ano da licenciatura em Educação e Formação do Instituto de Educação, no âmbito da unidade curricular Competências Emocionais, propusemos aos alunos que redigissem narrativas do seu quotidiano para incluir nos seus portefólios. Neste artigo analisamos aquelas relativas aos períodos de confinamento e pós-confinamento, as quais permitem-nos perceber vivências e dificuldades sentidas pelos estudantes ao longo do tempo, que emoções emergiram, as estratégias de regulação para lidar com essas dificuldades, bem como as aprendizagens realizadas, nomeadamente no que respeita ao desenvolvimento de competências emocionais. Consideram que esta situação constituiu uma restrição das suas liberdades, mas também uma oportunidade para desenvolverem estratégias de autorregulação, aprofundando dimensões relevantes para o seu percurso pessoal e académico.
\end{abstract}

Palavras-chave: Ensino superior; Covid-19; Competências emocionais; Estratégias de autorregulação; Emoções.

Times of crisis are complex periods where dynamics coexist that accentuate difficulties, but also that create opportunities for individual and collective overcoming, in the sense of greater equity and social inclusion. With the Covid-19 pandemic, changes were introduced in our lives. In Portugal, universities closed and replaced the 2 nd semester classroom classes with synchronous and asynchronous virtual classes. This situation was initially thought to be transitory, but remained until the end of the 2019/20 school year. As teachers of a group of 2 nd year students in the Education and Training course at the Institute of Education, within the scope of the Emotional Competences curricular unit, we proposed to students to write narratives of their daily lives to include in their portfolios. In this article, we analyze those related to the periods of confinement and post-confinement, which allow us to perceive experiences and difficulties experienced by students over time, what emotions emerged, the regulatory strategies to deal with these difficulties, as well as the lessons learned, namely with regard to the development of emotional skills. They consider that this situation constituted a restriction on their freedoms, but also an opportunity to develop self-regulatory strategies, deepening dimensions relevant to their personal and academic path.

Keywords: University education; Covid-19; Emotional competences; Self-regulatory strategies; Emotions.

*Contacto: cmsobral@ie.ulisboa.pt

ISSN: 2254-3139

www.rinace.net/riejs/

revistas.uam.es/riejs
Recibido: $\quad 29$ de julio 2020

$1{ }^{\text {a }}$ Evaluación: 20 de octubre 2020

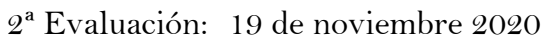

Aceptado: 16 de diciembre 2020 


\title{
1.Introdução
}

Vivemos num mundo caracterizado pela constante incerteza, vulnerabilidade e mudança, naquilo a que Bauman (2000) designou de modernidade líquida. Atualmente a enfrentar a epidemia Covid-19, a qual foi decretada pandemia internacional a 11 de março de 2020 pela Organização Mundial de Saúde (WHO, 2020). Em Portugal, foi declarado estado de emergência a 19 de março, o qual prolongou-se até 2 de maio de 2020. Nesta data, transitou-se para o estado de calamidade, iniciando-se um plano de desconfinamento em três fases: 4 de maio, 18 de maio e 1 de junho, com a reabertura gradual de vários setores de atividade (Decreto do Presidente da República n. ${ }^{\circ}$ 14-A/2020).

O Relatório Global da International Labour Organisation identificou os efeitos imediatos da pandemia na vida dos jovens de 18 a 29 anos, relativamente ao emprego, educação, saúde mental, direitos e ativismo social. Um dos aspetos realçados é o facto de metade da população jovem do mundo estar possivelmente sujeita a circunstâncias que causam ansiedade ou depressão devido ao Covid-19. É também evidenciado que a pandemia e as respetivas medidas de segurança agravaram as vulnerabilidades dos jovens no acesso aos seus direitos humanos, como sejam, o direito à participação cívica; a informação; habitação a preços acessíveis; serviços de saúde, inclusive para saúde mental; direitos no trabalho; bem como o direito a educação (Gonzalez, 2020).

Em Portugal, o estudo de Maia e Dias (2020), cujo objetivo foi analisar se os níveis de ansiedade, depressão e estresse em estudantes universitários portugueses se alteraram no período pandêmico, corrobora que esta pandemia provoca efeitos deletérios na saúde mental dos jovens adultos, concluindo que

\begin{abstract}
Os resultados confirmam um aumento significativo de perturbação psicológica (ansiedade, depressão e estresse) entre os estudantes universitários no período pandêmico comparativamente a períodos normais. Esses resultados vão ao encontro de outros estudos internacionais que analisaram o efeito psicológico da Covid-19 e de outras pandemias. (Maia e Dias, 2020, p. 6)
\end{abstract}

Dada a atual conjuntura, importa focar na criação de estruturas que respondam às necessidades de aprendizagem e desenvolvimento dos estudantes, dos docentes e das próprias instituições do ensino superior. Uma das soluções para assegurar a realização dos processos de ensino e aprendizagem tem sido o ensino online. Paula Peres (2000) acresce:

\begin{abstract}
A atualização pedagógica dos docentes é uma necessidade estrutural. O papel do docente no processo de ensino e aprendizagem online desenha-se, essencialmente, em torno dos "três Ms" (Motivar, Mediar e Medir). (...) importa ainda responsabilizar os estudantes das Instituições de Ensino Superior pela sua própria aprendizagem, $e$ pela capacidade de se envolverem nos processos de autoformação, e de criação dos seus planos, ambientes e redes pessoais de aprendizagem. (p. 28)
\end{abstract}

Na mesma linha de pensamento, Baxter Magolda (2002) afirma que o principal objetivo do ensino superior deve ser ajudar a capacitar os estudantes para serem autores das suas próprias vidas (self-authorship), i.e., pensarem de forma autónoma, fazerem escolhas e perseguirem os seus sonhos. Para o efeito, a autora defende que aqueles necessitam de boa companhia, mas adverte que: "Being good company for literally thousands of students, all of whom are on different journeys, is a complex challenge" (Magolda, 2002, p. 3).

Precisamos, cada vez mais, da companhia uns dos outros. Face às grandes crises, como a atual pandemia, o ser humano deve, pois, unir-se e fazer prevalecer o bem comum ao invés dos interesses individuais, como refere Echeita (2020): 


\begin{abstract}
¿Dónde hemos aprendido este sentimiento y dónde y cómo tenemos que enseñar -si cabe con más ahínco a la vista de las circunstancias actuales-, las actitudes, destrezas y comportamientos que sostienen esta importantísima cualidad y necesidad humana? Sin lugar a dudas, la respuesta es "en la escuela", desde la educación infantil a la universidad. Lo que uno quisiera es que esta crisis generada por el Covid-19 supusiera un antes y un después para colocar en el corazón del sistema y de la acción educativa, las formas de promover y cuidar este sentido de la pertenencia como tarea indispensable para nuestra supervivencia como especie. (...) el mejor modo de abordar esos problemas difíciles es la disposición a trabajar juntos, unidos por un fuerte sentimiento de pertenencia, colaboración y apoyo mutuo. (pp.10-11)
\end{abstract}

É neste contexto que se inscreve o presente texto, mais especificamente, no $1^{\circ}$ ciclo do ensino superior - licenciatura em Educação e Formação do Instituto de Educação da Universidade de Lisboa (IE-ULisboa), e particularmente no trabalho que duas docentes (autoras deste artigo) desenvolveram, no ano letivo de 2019/20, com o grupo de estudantes na Unidade Curricular Competências Emocionais (UC-CE). No âmbito da UC$\mathrm{CE}$, propusemos aos alunos que redigissem narrativas do seu quotidiano e é com base nessas narrativas que desenvolvemos o presente artigo. para o efeito, centrar-nos-emos em 4 questões de investigação: ¿Que dificuldades e desigualdades são identificadas pelos estudantes no decurso dos confinamentos sociais decretados devido à pandemia Covid-19? Que emoções e sentimentos emergiram durante este processo? Que estratégias desenvolveram para lidar com esta situação? Que aprendizagens, nomeadamente na área emocional, identificaram em si próprios decorrentes das suas experiências académicas e pessoais vividas durante este período de crise? Para responder a estas questões iremos analisar as suas narrativas, elaboradas ao longo do semestre, particularmente, aquelas redigidas durante a crise pandémica e durante a qual se suspenderam as aulas presenciais e se desenvolveu o processo educativo a distância, num período em grande parte pautado por confinamento social compulsório e em baixo de um decretado estado de emergência nacional, ao qual se seguiu um estado de calamidade com um progressivo desconfinamento social.

\title{
2. Emoções e competências emocionais
}

Tendo como conceitos centrais, para análise das narrativas, as emoções, estratégias de regulação e competências emocionais iremos fazer nesta secção uma breve apresentação dos referenciais que enquadram este estudo.

De acordo com Damásio (2017), a maquinaria dos afetos (pulsões, motivações e emoções), i.e., a emotividade, não é um processo fixo, mas sim mutável e, até certo ponto, educável, pois "Toda a espécie de fatores ambientais pode modificar a ativação emotiva durante o nosso desenvolvimento" (Damásio, 2017, p. 162), como sejam o ambiente da infância, em casa, na escola e no ambiente cultural.

Assim, ainda segundo Damásio (2010), considera-se que as emoções, enquanto componentes essenciais à manutenção da vida e maturação do indivíduo, são definidas como "inatas, automatizadas e estabelecidas pelo genoma", i.e., "O mecanismo essencial das emoções num cérebro normal é, com efeito, muito semelhante entre indivíduos (...)”. No entanto, é de realçar que “(...) temos uma considerável personalização das reações emocionais em relação ao estímulo causal. (...) Há outros aspetos interessantes nesta individualização. Influenciados pela cultura em que crescemos, ou como resultado da educação individual (...). As expressões emocionais (...) Podem ser moduladas e tornadas 
caracteristicamente pessoais ou sugestivas de um grupo social.” (Damásio, 2010, pp. 159160).

As emoções fazem parte do nosso quotidiano e em tempos de incerteza e crise, como da pandemia Covid-19, emergem com particular intensidade, e revelam-se claramente como fenómenos não apenas individuais, mas também coletivos, constituintes de um clima emocional societal que contagia os grupos, as instituições, toda a sociedade (de Rivera e Paez, 2007). É neste sentido que se entende o constructo de competências emocionais, as quais são julgadas, valorizadas e reforçadas de acordo com normas e valores prevalecentes no meio social.

O conceito de Inteligência Emocional (IE) surgiu na literatura científica através de Salovey e Mayer (1990) e, desde então, têm vindo a proliferar os modelos e a investigação neste campo. De um modo geral, é usual a distinção entre duas posições, o modelo de competências mentais e os modelos mistos. Segundo Schneider, Lyons e Khazon (2013): "Mixed (trait) models describe EI as skills, personality, and wellbeing (Bar-On, 1997; Goleman, 1995), whereas ability-based models describe EI as an intelligence comprising emotional abilities (Mayer, Caruso e Salovey, 1999, 2000)" (p. 909).

O presente artigo inclui-se no âmbito dos modelos mistos, como o de Goleman (1995, 1998) e o de Bar-On (1997). Optou-se por trabalhar estes modelos com os estudantes, pois da análise dos seus projetos/planos individuais (não abordados neste artigo), emergem outros aspetos para além de emoções e/ou inteligência como sejam a assertividade, empatia, otimismo, impulsividade, conscienciosidade, entre outros. São modelos que combinam dimensões sociais, emocionais, cognitivas, de personalidade e de desempenho no dia a dia.

Habitualmente, as competências emocionais são entendidas em torno de cinco áreas, de acordo com Goleman (2010), e podem ser representadas graficamente segundo dois eixos cartesianos: consciência-ação; centração no eu-no outro; e, segundo os quais, se organizam quatro quadrantes: autoconsciência; consciência social; auto-regulação e gestão dos relacionamentos (Figura 1).

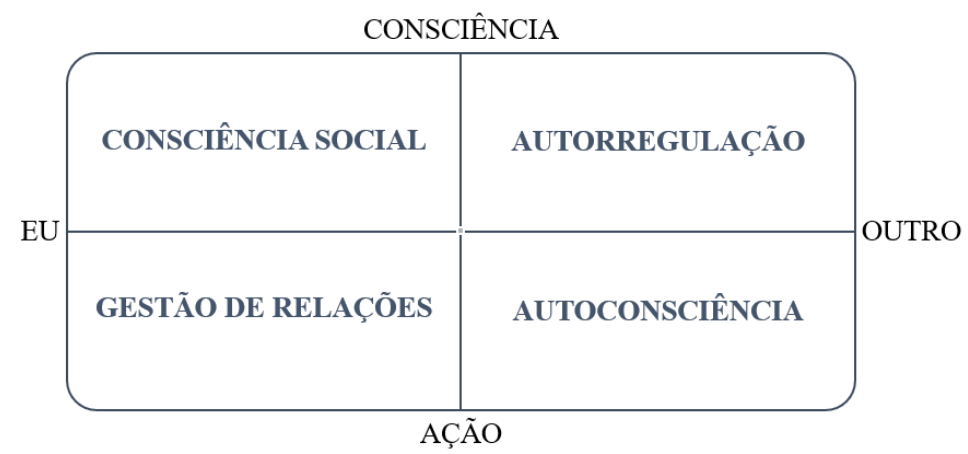

Figura 1. Modelo dos 4 quadrantes de Goleman. Áreas de competências emocionais Fonte: Adaptado de Goleman, Boyatzis e McKee (2002).

As áreas da regulação emocional dizem respeito a um conjunto de competências que orientam para a reflexão e ação sobre as emoções do próprio, sobre as situações que as provocam e sobre as relações que este estabelece com os outros, levando a selecionar 
estratégias para adequar as respostas emocionais aos objetivos definidos e às exigências dos contextos.

É, assim, constituída por várias avaliações de interação e repetição que conduzem à tomada de decisão do indivíduo (Gross, 2015). Este autor apresenta uma dinâmica do processo de regulação emocional, especificando três opções de monitorização, que conduzem a resultados adaptativos. A saber: i) Manter: continuar com a estratégia atualmente ativa, envolvendo subsequentes repetições; ii) Alternar: é avaliada positivamente uma estratégia alternativa; iii) Parar: a regulação é avaliada negativamente, cessando.

Neste modelo, as decisões de monitorização adequadas levam a resultados adaptativos, potencializando, assim, a motivação para a busca do bem-estar (Quoidback et al., 2010; Livingstone e Srivastava, 2012). O constructo autorregulação inclui duas propriedades básicas: (i) a primeira refere-se ao facto de ser um sistema motivacional e dinâmico de definição, implementação, avaliação e revisão de objetivos e estratégias; (ii) a segunda, à operacionalização de respostas emocionais (Batista e Noronha, 2018)

No Modelo de Processo de Regulação de Emoção de Gross (2015), a regulação emocional integra-se nos processos de regulação do afeto, os quais incluem estratégias de copinha (isto é, os processos cognitivos e comportamentais do indivíduo para lidar com problemas ou situações incomuns, através dos quais procuram restabelecer o equilíbrio psicológico e fisiológico), processos de regulação do humor e mecanismos de defesa. Enfatiza como aspetos nucleares da regulação emocional, o envolvimento de aspetos conscientes e inconscientes e assume não haver formas de regulação emocional melhores que outras, dependendo dos contextos. O modelo assenta na tomada de decisões, desde um ponto de partida: (i) seleção da situação, (ii) modificação da situação, (iii) direção da atenção, (iv) mudança cognitiva e (v) modulação da resposta. A primeira, implica uma avaliação das situações geradoras de emoções mais e menos agradáveis, com escolha de umas e evitamento de outras. A segunda, consiste numa mudança nas condições de uma situação, rumo ao alcance dos objetivos pessoais. A terceira, é influenciar as emoções, por distração ou concentração. A quarta, requer uma alteração na avaliação da situação, relativa à importância atribuída, aos pensamentos sobre aquela ou à própria capacidade do indivíduo. A última, compreende um processo de influência sobre as respostas fisiológicas ou comportamentais, como o exercício físico e relaxamento, ingestão de comida, ansiolíticos, drogas ou regulação da expressão emocional. Este modelo distingue, assim, processos de regulação emocional focados nos antecedentes e focados na resposta.

\section{Metodologia de pesquisa, participantes e procedimentos}

O processo metodológico central da investigação agora apresentada seguiu uma abordagem narrativa (Chase, 2011), que dá prioridade a um eu dialógico e à sua natureza relacional, pelo que a subjetividade é uma construção social, intersubjetivamente conformada pelo discurso comunicativo (Bakhtin, 2011, 2019). O jogo de subjetividades, num processo dialéctico, converte-se num modo privilegiado de construir conhecimento (Bolívar e Domingo, 2006). Neste sentido, "passar da aprendizagem prescritiva autoritária e primária para uma aprendizagem narrativa e terciária poderia transformar as nossas instituições educacionais e fazê-las cumprir a sua antiga promessa de ajudar a mudar o futuro social dos seus alunos" (Goodson, 2007, p. 251). A abordagem narrativa amplifica 
as vozes para que não fiquem silenciadas, fazendo uso da narração de histórias como meio de comunicar a realidade dos participantes a um público mais vasto. A investigação narrativa e as estratégias narrativas são, assim, uma forma de melhor compreender temas de experiência pessoal do ponto de vista do indivíduo (Riessman, 2008). Clandinin e Connelly (2000) enfatizam que a abordagem narrativa em contextos educativos vai para além de procurar ou ouvir uma história, possibilita descrições ricas de experiências e a exploração dos significados que os participantes atribuem àquelas. As narrativas têm o potencial de gerar relatos holísticos, interligando educação, experiência e vida, realçando a riqueza contextual e temporal distintas.

Na abordagem narrativa, as narrativas são, simultaneamente, método e objeto de estudo. Foi realizada uma análise temática (Riessman, 2005), procurando não fragmentar os dados e desvelando elementos comuns entre todos os relatos escritos dos participantes: "Emphasis is on the content of a text, "what" is said more than "how" it is said, the "told" rather than the "telling" (Riessman, 2005, p. 2).

Contexto do estudo, participantes e procedimentos

$\mathrm{O}$ trabalho desenvolvido com estudantes do $2^{\circ}$ ano da licenciatura em Educação e Formação do IE-ULisboa, faz-se na Unidade Curricular de Competências Emocionais (UC-CE), opcional do $2^{\circ}$ semestre. A UC-CE tem a duração de 1 h30 semanais, e centra-se no desenvolvimento de competências e conhecimentos relativos às dimensões emocionais e a problemáticas associadas, nomeadamente em contextos educativos. Desde que iniciou, em 2015/16, tem duas vertentes, uma individual e outra coletiva: propõe-se que os estudantes desenhem os seus próprios projetos de aprendizagem e de pesquisa, a partir de um processo de autodiagnóstico; e consequentemente desenha-se o projeto de turma. O primeiro com base num questionário sobre competências emocionais (Veiga-Branco, 2005) e o segundo orquestrando uma adaptação do programa da UC-CE às necessidades e interesses de cada turma, desenhado conjuntamente. As aulas teórico-práticas desenvolvem-se num processo cooperado, com a participação dos estudantes na proposta de atividades a desenvolver, que concorrem para a prossecução de ambos os projetos. Para além de práticas experienciais em sala de aula, onde se recorre a diversas formas de expressão (jogos, simulações, etc.), há oportunidade para fazer saídas a outros espaços dentro e fora da instituição universitária, com particular destaque para a participação ativa em eventos do IE-ULisboa. Destaca-se, ainda, a elaboração de um portefólio individual com descrições e reflexões das atividades desenvolvidas ao longo do semestre, que inclui o projeto individual de autoaprendizagem fundamentado, materiais pesquisados relativos a leituras, projetos e práticas educativas, bem como registos de situações do quotidiano.

No ano letivo de 2019/20, algumas dessas práticas não aconteceram e outras foram aprofundadas e tornadas mais sistemáticas, como foi o caso da monitorização do projeto individual e da escrita de narrativas do quotidiano. Estas são uma proposta educativa introduzida juntamente com muitas outras e que teve um desenvolvimento mais sistemático a partir do ano letivo 2018/19, mas que ganhou contornos próprios este ano letivo, emergentes da situação particular de pandemia e confinamento a que estivemos sujeitos a partir do dia 10 de março (a Universidade suspendeu todas as atividades letivas presenciais) até final do semestre (junho 2020), durante o qual as aulas passaram a acontecer através de processos a distância, sendo que a $3^{\mathrm{a}}, 4^{\mathrm{a}}$ e $5^{\mathrm{a}}$ aulas foram orientadas por processos assíncronos e as restantes 7 aulas por processos síncronos, via ferramenta virtual - plataforma Zoom. Quando foi decretado o confinamento teve de se rever os 
parâmetros e critérios de avaliação, atribuindo de modo explícito uma percentagem da avaliação final a este tipo de escrita. A meio do percurso na unidade curricular foi sugerido que escrevessem sobre a experiência que estavam a viver no tempo ou no rescaldo do tempo de quarentena, para aprofundar a sua reflexão sobre si e sobre os outros com quem se relacionam, para desenvolver o seu autoconhecimento e autorregulação de emoções e relações. No final do semestre, verificou-se um aumento substancial de narrativas em relação aos anos letivos anteriores.

No que respeita aos participantes, a turma era constituída por 24 estudantes, dos quais 22 do sexo feminino e 2 do sexo masculino, com idades compreendidas entre os 20 e 45 anos, sendo que a maioria tinha 20. Após a clarificação de que o processo educativo seria objeto de investigação e o esclarecimento de que os dados sobre suas produções escritas poderiam ser trabalhados caso concordassem, obtivemos nas primeiras aulas presenciais um total de 11 consentimentos informados por escrito. Centrar-nos-emos na apresentação geral dos procedimentos e numa análise genérica de conteúdos das narrativas, sendo que a apresentação de textos dos estudantes se circunscreve apenas às narrativas dos estudantes que aceitaram que os seus dados fossem objeto de análise, mantendo como acordado o anonimato. Deste modo usaremos, para identificação dos excertos, nomes fictícios e o número da narrativa (A, N 1, 2, 3, ...), pois cada estudante redigiu frequentemente mais do que uma narrativa sobre o período da pandemia.

\section{Participantes e procedimentos de investigação}

A turma da UC-CE era constituída por 24 estudantes, dos quais 22 do sexo feminino e 2 do sexo masculino, com idades compreendidas entre os 20 e 45 anos, sendo que a maioria tinha 20. Contudo, apenas 11 estudantes (todas do sexo feminino) devolveram os consentimentos informados assinados, ainda no decurso das aulas presenciais, a fim de participarem da investigação. Num primeiro contacto com os dados contabilizou-se um total de 43 narrativas, numa média de 3,9 narrativas por aluno. De entre as 43 narrativas, 24 reportavam-se ao período de quarentena, numa média de 2,2 narrativas sobre quarentena por aluno. Desde o início das aulas, foi clarificado que o processo educativo seria objeto de investigação e esclareceu-se também que as produções escritas dos alunos seriam trabalhadas, mantendo o anonimato. Deste modo, foram utilizados nomes fictícios e o número das narrativas desse mesmo estudante (Nome, N1, 2, 3, ...), para identificação dos excertos em cada uma das diferentes narrativas.

Na apresentação de resultados que se segue, está subjacente uma leitura interpretativa das narrativas redigidas pelos 11 alunos que se reportam ao tempo da pandemia, na qual damos particular espaço às vozes dos estudantes. Começamos por fazer uma breve análise global na qual identificamos, de forma genérica, os contextos, as emoções e as dimensões e eixos de análise, que sobressaíram nas narrativas dos estudantes.

\section{Resultados}

Ao longo deste ponto analisamos as 24 narrativas dos 11 estudantes, referentes aos períodos de confinamento e pós-confinamento. Numa análise global, as narrativas são alusivas (ainda que não de modo exclusivo): ao próprio; à família; à comunidade, imediata, como os amigos e os colegas de atividades extracurriculares e institucional, como a escola e o emprego; e à sociedade (país e mundo). 
Analisando o conjunto das narrativas do ponto de vista emocional, predomina numa primeira fase exemplos de emoções e sentimentos relativos ao medo e ansiedade, com algumas afirmações de maior intensidade como o terror e a angústia. Também a saudade, nostalgia, solidão, tristeza, desgosto e desânimo. Estas emoções e sentimentos são oscilantes e após uma primeira fase mais crítica começam a aparecer emoções e sentimentos mais positivos, que estão associados à superação de dificuldades e a perceberem oportunidades nas situações vividas. Aí surgem referências ao orgulho, calma, alegria, esperança, bem-estar, chegando alguns estudantes a ter afirmações relativas a emoções mais intensas como felicidade e euforia. No que respeita ao reconhecimento de competências emocionais presentes nessas narrativas, salienta-se a expressão de emoções, a autorregulação, autoestima, a autoconsciência, a empatia e gestão de relações. Identificamos, ainda, a necessidade de desenvolvimento a nível emocional, nomeadamente na expressão de emoções e de afetos e na regulação de ansiedade e da impulsividade.

Numa análise mais detalhada, emergiram dos dados 4 dimensões, a saber: dificuldades, emoções, estratégias de autorregulação e competências emocionais desenvolvidas. Em cada narrativa procurámos identificar a presença dessas dimensões, sem desconstruir a sequência do discurso, de forma a não perder as relações de significado estabelecidas pelos estudantes. Deste modo, foi possível perceber as conexões que os estudantes faziam e, a partir dessas relações identificadas pelos próprios, interpretar os dados à luz de dois eixos temáticos principais: 1) a relação entre dificuldades, emoções associadas e estratégias de autorregulação; 2) a relação entre competências emocionais e as experiências que se constituíram como oportunidades de aprendizagem.

\subsection{Dificuldades, emoções associadas e estratégias de autorregulação}

No que respeita às narrativas redigidas pelos estudantes sobre a pandemia, escolhemos apresentar e refletir sobre alguns excertos nos quais é mais clara a reflexão sobre dificuldades sentidas pelos estudantes relativas ao período de confinamento e sobre suas estratégias de (auto)regulação.

De entre as dificuldades sentidas, destacam-se questões relativas ao isolamento e ao sentimento de perda a nível académico e afetivo, tendo essa perda sido agravada pelo que, em substituição, constituiu um acréscimo de stress e de ansiedade e medo da incerteza:

As nossas aulas foram interrompidas por uma situação atípica, e durante algum tempo senti-me completamente perdida em relação ao que fazer nesta unidade curricular, para dizer a verdade em relação a praticamente todas, onde deveria procurar informação sobre a competência que queria ver desenvolvida, a minha diferença de idade em relação aos meus colegas e a minha vida com uma realidade diferente faz com que não tenha relações que noutras circunstâncias seriam normais, portanto senti-me perdida e isolada. (Alana, N9)

Uma das medidas tomadas, e a que mais me afeta, foi o encerramento da faculdade. Compreendo que essa medida foi tomada para manter a segurança de todos e aceitoa. Mas esta situação remete-me para um misto de emoções, por um lado, tenho medo porque não temos uma "cura" para o vírus e qualquer pessoa pode ser afetada. Por outro lado, instala-se a ansiedade de ter a vida, tanto académica como pessoal em "standby", pois não é seguro sair de casa e só de pensar em ficar fechada em casa é surreal. (Alice, $\mathrm{N} 1$ )

Porém este isolamento específico tirou-me muita coisa, tirou-me a minha namorada, as minhas amigas, os trabalhos de grupo na biblioteca que era mais um convívio do que um trabalho árduo, tirou-me o "trabalho de campo" de Seminário que eu adorava e no fim da investigação, tirávamos sempre um tempo para ir passear pelo local, 
conhecer melhor Lisboa, conviver um pouco, tirou-me as horas de almoço a apanhar sol junto ao lago da faculdade, os passeios por Lisboa e pelo shopping. Senti muita falta da minha cidade (Abrantes) enquanto ficava por Lisboa. (...) Todos os dias vejo a percentagem de aumento de vítimas do Covid-19 com a esperança que esteja a diminuir e rezo para que encerrem as aulas. Este método não é produtivo para nenhum aluno, o trabalho dobrou e eu só consigo limitar-me a cumprir prazos. Só. Pensava que quando a quarentena começasse iriam optar por adiar as aulas até ao próximo ano letivo, mas para meu desgosto decidiram cumprir aulas síncronas sem se darem conta que nos estão a tirar parte da experiência universitária e a substitui-la por montes de trabalho exaustivo e aulas virtuais onde metade dos professores não sabem trabalhar. (Brenda, N2)

Para muitos é apenas ficar uns dias em casa, para nós estudantes, e falo no meu caso, são prazos de trabalhos apertados, cancelamento de reuniões relacionada com trabalhos importantes, sentir que não vamos conseguir manter os nossos resultados no final do semestre, mas pior ainda, não saber quando poderemos voltar à normalidade. Não saber quando iremos voltar à nossa rotina, quando poderemos sair à rua sem medos, beber café com os amigos, estar com a família, voltar a fazer o que sempre fizemos sem receio é o que mais confusão me faz. (Alice, N1)

Talvez esteja relacionado com o estado de emergência e a incerteza do que irá acontecer amanhã que me tem provocado uma grande ansiedade manifestando-se de diferentes formas, ora fico deprimida e não consigo fazer nada, ora estou cheia de energia e otimismo e sinto que consigo fazer e superar tudo isto. (Alana, N5)

De modo particular, a situação de alunos Erasmus trouxe dificuldades acrescidas, pois alguns ficaram retidos em Portugal sem poder voltar a suas casas de família, sem ter o conforto afetivo daqueles que lhes são mais próximos, instigando uma constante preocupação:

Con todo esto que está pasando sobre la pandemia, es normal tener miedo a que puedan enfermar miembros de tu familia. Yo estoy en Lisboa, y toda mi familia está en España. Cada día siento miedo a que pueda tocarle a alguien de mi familia esta enfermedad, y sobretodo siento mucho miedo por mis abuelos. Son personas mayores y son un grupo de riesgo. Por eso, tengo terror a qué pueda perderlos y que yo esté fuera de mi país. No me gusta pensar en esto porque me puedo llegar a sentir culpable y egoísta de haber venido a vivir esta experiencia. (Carmo, N1)

Este día [22 de marzo] comenzó siendo un dia normal, con las emociones muy neutras y estables. Por la noche tuve una discusión con una persona muy importante para mi. Fue por un chat puesto que yo estoy en Lisboa y el en España. Fue y aún es un tema muy complicado de resolver a nivel emocional. Sentí cabreo, decepción, pena y rabia. Todo esto lo sentí conmigo misma porque yo tuve la culpa de todo, por lo tanto sentí muchísima ansiedad de no saber gestionar la situación. Día a día me convezco de que debo apartar un poquito ese tema de mi mente y volver a retomarlo cuando sea posible solucionarlo cara a cara con la persona que lo tengo. (Diana, N1)

No que respeita a estratégias de regulação, algumas foram induzidas pela própria unidade curricular e suas propostas, outras foram desenvolvidas pelos próprios estudantes. Não obstante, inicialmente, o choque da situação induziu uma desorientação inicial, emoções de ansiedade e angústia e as estratégias utilizadas foram respostas seletivas de evitamento e inércia, mas também de concentração obsessiva na situação e de procura de informação (Gross, 2015):

Esta semana tem sido particularmente estranha, as notícias do Covid-19 começam a deixar-me alarmada e preocupada com as previsões para o nosso país e as notícias que chegam de fora. (...) senti um grande vazio, ansiedade e desorientação, não que me faltem coisas para fazer em casa, mas pelo futuro que nos espera que não sabemos como será. (Alana, N1) 
Escrevo esta reflexão como forma de relatar como foi a minha experiência, o que vivi e senti durante os meus quase três meses de distanciamento social. Gostaria de começar por dizer, que no início foi um pouco difícil assimilar o que realmente estava a acontecer, não pelo facto de duvidar da seriedade do vírus e da sua capacidade de propagação. Mas pelo simples facto de nunca sequer ter pensado que isto poderia acontecer alguma vez na minha vida, pois ao parar para pensar, isto tudo parece uma história dos filmes que eu costumo ver. Quando foi declarado o estado de emergência, e tivemos de deixar de ir à faculdade, de estar com a pessoa que amo, com os meus familiares, ou simplesmente ir comer um gelado ao jardim à hora que me apetecia, foi difícil de assimilar. No primeiro mês, apesar de não sentir ansiedade para sair à rua, $e$ de aparentemente não ter experienciado nenhum sentimento negativo sobre o distanciamento, eu não conseguia fazer nada para além de passar os dias deitada. Não me senti mal psicologicamente, nem angustiada, simplesmente não tinha qualquer tipo de motivação para fazer absolutamente nada. Acabei por trocar o dia pela noite $e$, por isso, passava as noites acordadas e o dia sonolenta e lá acabava por dormir 4/5 horas para conseguir descansar o bocadinho que fosse. Confesso que até agora não percebi o porquê de isto ter acontecido mas na altura não relutei contra isso, deixei que o meu corpo e a minha mente fizesse aquilo que eles sentiam que era o melhor para eles naquele momento. (Camila, $\mathrm{N} 1$ )

Entre não poder sair de casa, as notícias diárias em relação ao Covid-19, os trabalhos da faculdade e as aulas online confesso que bater com a cabeça nas paredes já esteve mais longe dos meus planos. (...) tem sido inevitável estar preocupada com este assunto, e tem sido muito complicado gerir todos os trabalhos que são pedidos para fazer neste tempo em que não é possível haver aulas presenciais. Confesso que os primeiros dias foram difíceis no que toca minha à ansiedade. Ver as notícias assustava-me, andava o dia todo a pensar no mesmo e sempre preocupada com os meus familiares que pertencem ao grupo de maior risco. Conseguir dormir a horas decentes era impensável e ficava acordada até às 5 da manhã só a pensar, e a pensar... A minha alimentação estava "um pouco por todo o lado" e sem grandes horários. (Débora, N1)

É tudo muito confuso e sobretudo incerto e provoca um nível de ansiedade que nunca tinha experimentado, ao ponto de interferir com o sono. O cérebro diz-me que tenho milhentas coisas para fazer, entre trabalhos para a faculdade e tarefas de casa, apoio às minhas filhas que também estudam, neste momento em casa, e contribuir para o bom ambiente vivido em casa uma vez que estamos todos confinados a ela, o corpo diz-me que quer ficar quieto, em silêncio. Fiquei assim durante alguns dias... Li o livro de Goleman et al., Inteligência Emocional: Empatia. (Alana, N4)

Numa fase posterior, os alunos conseguiram modificar a sua estratégia no sentido de redirecionar a sua atenção, de mudar cognitivamente a sua perceção da situação e de modular a sua resposta através de rotinas saudáveis, o que favoreceu o desenvolvimento das suas competências emocionais, nomeadamente na área motivacional e na autoestima e aceitação de si próprios. No caso concreto das alunas mencionadas, referem:

Com o passar do tempo, isso mudou, passei a ir dormir a horas e a acordar às $7 \mathrm{~h} d a$ manhã todos os dias, passei a sentir-me bem comigo mesma e a criar motivação para as coisas que durante um mês não tinha conseguido fazer. Quando isso aconteceu, foi a melhor fase da minha quarentena, pois sentia-me feliz e bem comigo mesma, passei a cuidar, dar mais atenção a mim mesma e a mimar-me, o que querendo ou não, deume mais forças para continuar assim no resto da quarentena. Bem, o que eu refleti e concluí disto tudo foi que é importante respeitarmo-nos e às nossas emoções. Há dias bons e dias maus, e está tudo bem. Sei que há alturas em que mesmo quando estamos mais em baixo é necessário puxarmos por nós e continuarmos firmes, no entanto, acho que ceder às vezes é importante para que mais para a frente possamos reerguer-nos mais fortes. (Camila, N1)

Tomei a decisão de criar uma rotina e fazer um plano diário, para sentir que sou mais produtiva e para evitar procrastinar, isto é, ver filmes o dia todo no sofá. Todos os dias acordo por volta das 10:45 e faço exercício em casa, um pequeno treino de 16 minutos mas que me faz sentir muito melhor para continuar o dia; de seguida 
preparo-me como se fosse sair de casa (tomo um banho, visto uma roupa confortável que não seja o pijama e preparo o meu almoço), verifico a minha lista de tarefas de trabalhos da faculdade para o dia, e levo o meu computador, cadernos e agenda para a sala, de modo a servir de escritório e assim poder distanciar o meu espaço de lazer (quarto) e o de trabalho (sala). Quando termino o que tenho para fazer automaticamente sinto-me mais leve e como se tivesse o dever cumprido, então aí, posso ir ver um filme, uma série ou até experimentar receitas novas (tenho feito bastantes bolos). Aproveito para falar com os meus amigos por videochamada, visto que estamos todos na mesma situação e uma atividade que descobri que me relaxa bastante é pintar. Encontrei por casa um livro de mandalas para colorir e passo horas naquilo. Em suma, acho que a partir de agora vou conseguir lidar muito melhor com os dias que se seguem, que não serão poucos, mas que no fim tudo vai compensar e todos juntos vamos ultrapassar esta fase menos boa. (Débora, N1)

Finalmente resolvi acordar para a vida, desafiada pela minha filha mais velha voltei a fazer jogging, primeiro fico exausta, depois de um duche sinto-me com energia para mover qualquer coisa, tenho também intensificado os exercícios de mindfulness que me ajudam na concentração e no afastamento de pensamentos negativos, espero que a partir de agora consiga uma nova rotina concentrada no que realmente é importante neste momento, resignando-me a uma nova realidade, espero que temporária...

(Alana, N4)

Outros estudantes relatam, no mesmo sentido, estratégias de modulação de resposta perante a situação de stress, nas quais se destaca o exercício físico, o relaxamento, o cuidar de si próprio, a relação afetiva com terceiros. Outros, ainda, mencionam outro tipo de estratégias focadas nos antecedentes, dirigindo a atenção por concentração em algumas tarefas e distraindo a atenção em relação à situação da pandemia, com consequências positivas na sua autoestima (Gross, 2015):

Em relação ao sair de casa, fi-lo com o intuito de passear mais a minha cadela, fazer um pouco de exercício e apanhar sol. Esta estratégia ajudou-me no sentido em que consegui tirar um tempo para mim, longe de todos os mil trabalhos em atraso que me causavam bastante stress e ansiedade. (...) considero que tirar este tempo me fez muito bem para diminuir o nível de stress acumulado e cuidar um pouco mais de mim. (...). Comecei por fazer Videochamada com as minhas amigas com o objetivo de realizarmos em conjunto trabalhos académicos, porém, posteriormente, resolvi começar a fazer o mesmo por lazer, como ver um filme, conversar, etc. Considero este método bastante essencial quando se quer aumentar a autoestima pois permite-nos conversar com outras pessoas para que não nos sintamos sós, especialmente em tempo de quarentena. A solidão é muitas vezes a minha maior inimiga pois, apesar de me sentir bem por vezes, quando é demais consome-me de uma maneira que só quem se encontra numa situação semelhante compreende. (Brenda, N1)

Graças ao Projeto Pessoal, considero que tenho andado um pouco mais calma pois comprometi-me a realizar certas atividades que me têm mantido distraída e distante de toda a situação atual. (Brenda, N5)

Nestas circunstâncias excecionais e tendo em conta que era uma situação geral, envolvendo todos num processo comum, alguns preocuparam-se em propor atividades para os colegas, a fim de proporcionar momentos de experiência pessoal de partilha e de autoconhecimento e autorregulação:

Gracias a estas reflexiones, he pensado en proponer una actividad en el foro de clase sobre el duelo, para que todos sepamos detectar lo que es el duelo y cuáles son sus fases. (Carmo, N1)

Experimentei o mindfulness, é muito complicado fazer este exercício em minha casa, somos cinco pessoas e a casa é pequena. No entanto penso que consegui fazer bem, utilizei a sugestão da colega Alexandra, quando termino é como se voltasse de outra dimensão para a realidade. (Alana, N3) 


\subsection{Oportunidades de aprendizagem para o desenvolvimento de competências emocionais}

Apresentamos agora excertos de narrativas redigidas nos quais é mais clara a relação identificada pelos estudantes entre a experiência de confinamento compulsivo e o desenvolvimento de aprendizagens, nomeadamente de competências emocionais, ao nível do autoconhecimento, da consciência social, da autorregulação e da gestão de relacionamentos.

Para alguns estudantes o confinamento impeliu ao ensaio de estratégias pouco usuais e o desenvolvimento de algumas competências a que se tinham proposto nos seus projetos individuais:

Acho que relativamente ao facto de me expor e ter de intervir perante um grupo de pessoas, tem sido das coisas que mais tenho conseguido trabalhar, ainda que, neste momento de pandemia em que nos encontramos, as intervenções que faço são protegidas pelo computador e não presencialmente. (Bianca, N1)

Estou em casa (...) trabalho numa creche, mas diariamente envio ideias de atividades para os pais fazerem com os filhos. Hoje foi dia de reunião [de equipa, via zoom] e uma das minhas colegas sugeriu que quem quisesse "embelezar" os seus vídeos com animações ou música enviasse para ela, pois faria a sua edição. (...) mas, porque não explicar como se faz uma vez que todas têm condições e tempo para isso? Eu intervim e expliquei que bastava utilizar o editor de vídeo do computador ou utilizar uma das aplicações disponíveis na web. (...) penso que [foi] mais simpático ensinar as colegas que não sabem, contribuindo para que estas também evoluam no desenvolvimento das suas competências (...) consegui pôr-me no lugar do outro, das minhas colegas que não sabem como se faz a edição dos vídeos e que talvez gostassem de aprender...

(Alana, N3)

Está siendo un dia [10 de abril] de "hermaneo". Esto quiere decir que todas las niñas del piso nos ayudamos mutuamente en todo momento, hacemos cosas en común como puede ser la comida y las actividades de aula. (Diana, N1)

A maioria dos estudantes consegue ver nesta situação vantagens, apesar de todas as dificuldades e de preferirem que o semestre tivesse ocorrido de outro modo, esta terá sido uma oportunidade de encontro consigo mesmo, de reflexão sobre o sentido da vida e de valorização do que é importante:

Decidi escrever, agora que estamos a voltar ao normal aos poucos, como é que tem sido a minha experiência em relação ao desconfinamento e como é que a minha ansiedade se tem comportado nestes últimos meses. Posto isto, e por ser um pessoa que pensa muito nas coisas, e se preocupa bastante no geral, com tudo, o confinamento não foi a coisa mais fácil pela qual tive de passar, uma vez que tive de aprender de uma maneira quase como obrigatória a estar mais sozinha e a saber aproveitar a minha companhia, porque acho que às vezes estamos tão habituados a estarmos rodeados pelos nossos amigos e família, e tentamos evitar fazer certo tipo de coisas sozinhos, que nos esquecemos que conseguimos, muitas vezes, ser a nossa melhor companhia. (...) e pude realmente perceber o significado de "nós somos a nossa melhor companhia"; sinto que cresci mais nestes últimos três meses do que num ano inteiro, porque me foquei nas coisas que eu gosto de fazer, trabalhei para mim e esforcei-me para me sentir bem. Sin embargo, estoy muy contenta porque he conocido a mis compañeras de piso que sé que serán unas amistades que perdurarán. (Débora, N2)

Estoy aprendiendo y reflexionando mucho sobre esta cuarentena. He aprendido que no puedes dejar para otro día lo que quieres hacer, que tenemos que valorar los pequeños detalles y disfrutar de los días al máximo. Espero que pueda disfrutar aunque sea en el mes de junio de Portugal, poder viajar y exprimir el mes al máximo. (Carmo, N2) 
É sem dúvidas uma nova experiência que terei que arcar sem muita opção de escolha. Claro que preferia que tudo estivesse normal e que as aulas continuassem a ser realizadas como era previsto, porém eu tento olhar esta situação de uma forma mais positiva (o quanto possível). Esta situação é vantajosa a meu ver a nivel pessoal, pois exige muito mais de cada um de nós, no que diz respeito a necessidade (mais do que nunca) de sabermos enquanto estudantes, gerir o nosso tempo e atividades, fazendo com que cresçamos como indivíduos e futuros profissionais. (Carmelita, N1)

Há também quem relate aprendizagens emocionais de autorregulação da ansiedade, pela aprendizagem de estratégias de modulação, através de exercícios de meditação.

Faço anos daqui 4 dias, e confesso que é difícil fazer anos em quarentena, mas estou animada na mesma! No outro dia tive uma discussão em casa e a minha ansiedade piorou, mas consegui controlar bastante bem, com alguns exercícios de respiração e concentração, por isso estou orgulhosa. (Débora, N3)

Empezaré a hablar de mi gran descubrimiento en esta asignatura: el mindfulness. Nunca antes habia hecho mindfulness, y más, no sabía de que trataba ni qué beneficios tiene. Ahora que la he practicado, he encontrado una mejoría a la hora de canalizar mis emociones. Me ha ayudado mucho a controlar el estrés y la ansiedad, porque antes solía tener muy altos los niveles de estrés, y por consecuencia de este, tenía pequeños ataques de ansiedad. Ahora, gracias al mindfulness y algunos consejos que explicaron mis compañeros en el aula de estrés y ansiedad, lo controlo mucho mejor y evito que se den situaciones de este tipo. Para reducir mi ansiedad y todas las emociones negativas he recurrido a la meditación antes de ir a dormir y también estoy aprendiendo a darle la importancia que de verdad se merecen. (Diana, N2)

Durante a meditação sinto-me bem e penso que consigo atingir a calma pretendida durante alguns minutos. (Alana, N5)

Com o desconfinamento novas readaptações têm de ser feitas, regressam os medos, mas também as esperanças e, sobretudo, a confiança de que se sai enriquecido destas experiências, mais focado nos seus objetivos e bem-estar:

\begin{abstract}
Agora que as coisas estão a voltar aos poucos ao normal, é assustador, porque para mim é muito difícil abstrair-me do medo que tenho do vírus, pois moro com uma pessoa que pertence ao grupo de risco, e sinto que ainda vai demorar muito tempo para que consiga descontrair um bocado e não estar sempre preocupada com tudo. No entanto, aos poucos sei que as coisas vão melhorar, e vamos ter a nossa vida de volta. Mas uma coisa é certa, saio desta experiência uma pessoa muito mais crescida, com os pés bem assentes na terra e mais objetivos para o futuro. Preocupo-me mais comigo e com o meu bem-estar, por isso, nem tudo nesta situação foi mau. (Débora, N2)
\end{abstract}

No entanto resta-nos esperar, manter a fé e pensar positivo. Acreditar que VAI FICAR TUDO BEM! (Alice, N1)

A identificação, reconhecimento e desenvolvimento de competências emocionais foi uma realidade exequível, bem patente nas narrativas por nós analisadas. Salientamos, ao nível da autoconsciência, um maior conhecimento de si próprios; ao nível da consciência social, um acréscimo de atenção empática; ao nível da autorregulação, a experimentação de estratégias diversificadas; e ao nível da regulação de relacionamentos, a prioridade dada à colaboração, para o bem comum.

Em suma, estes estudantes, futuros profissionais de educação e formação, sentiram e valorizaram a importância de trabalhar o campo emocional, no dia-a-dia, de forma agora mais consciente e atenta, tendo também ficado munidos de ferramentas (as quais podem ir aprimorando), que lhes serão úteis ao longo da vida. 


\section{Discussão e conclusões}

Os estudantes que participaram nesta investigação são críticos em relação a questões de justiça criadas por estas circunstâncias adversas, percebendo os seus direitos ameaçados, enquanto estudantes e cidadãos, nomeadamente os de participação ativa na comunidade escolar. São, no entanto, pouco críticos em relação a questões de desigualdade social. Não deixam, porém, de denunciar restrições nas oportunidades que normalmente lhes são oferecidas pelo envolvimento na escola, ao nível da intensificação de relações com colegas e docentes, que tantas vezes acontecem de modo informal nos espaços fora da sala de aula. Restrições ampliadas fora da universidade, pela ausência de espaços de convívio em outros contextos sociais e culturais. Repentinamente confinados nos seus habitats familiares (ou residências universitárias), alguns impedidos de regressar aos seus países de origem (quando estavam a iniciar seus processos de mobilidade Erasmus), começam por sentir intensamente emoções como o medo, a ansiedade, a tristeza, a angústia, o desânimo, o torpor, que com o tempo se ampliam para outras emoções, como a nostalgia, saudade, solidão.

Às dificuldades com a mudança, num primeiro embate com a adaptação, dificuldades também dos professores e das escolas à mesma situação, acrescem dificuldades de aceder a recursos como a internet, dificuldades financeiras e preocupações a nível da saúde, consigo próprios, com familiares e amigos. Dificuldades sentidas de modos distintos consoante as suas circunstâncias pessoais e formas próprias de lidar com as adversidades. Muitos, no entanto, conseguiram conscientemente estar atentos às expressões emocionais, nomeadamente àquilo que sentiam e como se expressavam, através das monitorizações sistemáticas dos seus projetos individuais e consequentes adaptações das estratégias em uso, por forma a superar as dificuldades, progressivamente (Gross, 2015). Este processo passou pelas auto-observações, registos com descrições de situações e consequentes reflexões.

Deste modo, cada estudante foi (e/ou está ainda), ao seu ritmo, experienciando diversificadas formas de regulação emocional, quer pela criação de rotinas de trabalho e de lazer, pelo apoio nas suas redes relacionais, o investirem nos estudos e, gradualmente, foram percebendo esta situação de crise como uma oportunidade para aprofundar o autoconhecimento e desenvolver aprendizagens diversas, nomeadamente de autorregulação. Ou seja, encontraram motivação para definir, implementar, avaliar e rever os seus objetivos e estratégias, operacionalizando respostas emocionais, para levarem avante os objetivos a que se propuseram nos seus projetos individuais (Batista e Noronha, 2018). A nível emocional começaram a sentir orgulho em si próprios, aumentando sua autoestima, a esperança no futuro e, principalmente, o bem-estar (Quoidback et al., 2010; Livingstone e Srivastava, 2012). Desejam, ainda, assim, voltar à escola, ao convívio, à vivência em ambiente universitário, anseiam pelo fim da pandemia e pela liberdade que lhes foi sonegada durante este período.

Por seu lado as escolas precisam aprender, com esta experiência, a encontrar caminhos mais inclusivos, de maior equidade, encontrando soluções diversificadas para estudantes com problemas imprevistos e também eles diversos, acompanhando-os de perto, mesmo que a distância, procurando apoiar cada um, na superação das suas dificuldades e no aprofundamento dos seus projetos e das suas aprendizagens. Unidos por um sentimento de pertença, trabalhando juntos para superar os problemas. Enfrentando estes, unidos por um sentimento de pertença e colaboração (Echeita, 2020). Procurando que todos, sem 
exceção, participem nos processos e tenham sucesso nos resultados alcançados. Não desistindo da sua missão de formar, investigar e contribuir para o desenvolvimento das comunidades e sociedade em geral, precisam estar disponíveis e abertas para responder com flexibilidade a circunstâncias excecionais, criando medidas também excecionais, mas que se poderão tornar comuns no futuro, com proveito para todos. E retomando, logo que possível, os espaços de encontro, de debate, de produção, não para fazer exatamente o mesmo, mas para fazer melhor, sempre e cada vez mais e melhor, no sentido de uma maior justiça social e bem comum.

\section{Referências}

Bakhtin, M. (2011). Estética da criação verbal. Martins Fontes.

Bakhtin, M. (2019). O homem ao espelho. Apontamento dos anos 1940. Pedro \& João Editores.

Bar-On, R. (1997). The emotional quotient inventory (EQ-i): A test of emotional intelligence. MultiHealth Systems.

Batista, H. H. e Noronha, A. P. (2018). Instrumentos de autorregulação emocional: Uma revisão de literatura. Avaliação Psicológica, $17(3)$, 389-398.

https://doi.org/10.15689/ap.2018.1703.15643.12

Bauman, B. (2000). Liquid modernity. Polity Press.

Baxter Magolda, M. (2002). Helping students to make their way to adulthood: Good company for the journey. About Campus, 6(6), 2-9.

Bolívar, A. e Domingo, J. (2006). Biographical-narrative research in Iberoamerica: Areas of development and the current situation. Forum: Qualitative Social Research, 7(4), 1-41. https://doi.org/10.17169/fqs-7.4.161

Chase, S. E. (2011). Narrative inquiry: Still a field in the making. En N. K. Denzin e Y. S. Lincoln (Eds.), Handbook of qualitative research (pp. 421-434). Sage Publications.

Clandinin, D. J. e Connelly, F. M. (2000). Narrative inquiry: Experience and story in qualitative research. Jossey-Bass.

CNE. (2019). O estado da educação 2018. CNE.

Damásio, A. (2010). O livro da consciência. Temas e Debates.

Damásio, A. (2017). A estranha ordem das coisas. A vida, os sentimentos e as culturas humanas. Temas e Debates.

de Rivera, J. e Paez, D. (2007). Emotional climate, human security, and cultures of peace. Journal of Social Issues, 63(2), 233-253. https://doi.org/10.1111/j.1540-4560.2007.00506.x

Echeita, G. (2020). La pandemia del Covid-19. ¿Una oportunidad para pensar en cómo hacer más inclusivos nuestros sistemas educativos? Revista Internacional de Educación para la Justicia Social, 9(1), 7-16.

Gonzalez, S. P. (2020). Touth and Covid-19: Impacts on jobs, education, rights and mental well-beingsurvey report 2020. International Labor Organization (ILO).

Goleman, D. (1995). Emotional intelligence. Bantam Books. https://doi.org/10.1037/e538982004-001

Goleman, D. (1998). Working with emotional intelligence. Bantam Books. https://doi.org/10.1002/ltl.40619981008 
Goleman, D. (2010). Inteligência emocional. Temas e Debates.

Goleman, D., Boyatzis, R. e McKee, A. (2002). Primal leadership: Realizing the Importance of Emotional Intelligence. Harvard Business School Press.

Goodson, I. (2007). Currículo, narrativa e o futuro social. Revista Brasileira de Educação, 12(35), 241-252. https://doi.org/10.1590/S1413-24782007000200005

Gross, J. J. (2015). Emotion regulation: Current status and future prospects. Psychological Inquiry, 26(1), 1-26. https://doi.org/10.1080/1047840X.2014.940781

Livingstone K. M. e Srivastava, S. (2012). Up regulating positive emotions in everyday life: strategies, individual differences, and associations with positive emotion and well-being. Journal of Research in Personality, 46(5), 504-5 16. https://doi.org/10.1016/j.jrp.2012.05.009

Maia, B. R. e Dias, P. C. (2020). Ansiedade, depressão e estresse em estudantes universitários: o impacto da Covid-19. Estudos de Psicologia, 37, e200067. https://doi.org/10.1590/1982-0275202037e200067

Oliveira, V. M. e Navega, F. (2017). Relatório nacional sobre a implementação da Agenda 2030 para o desenvolvimento sustentável. Ministério dos Negócios Estrangeiros.

Peres, P. (2020). Covid-19 e a luta pela sobrevivência. Governação, IES, docentes e estudantes, Ensino Superior, 68, 26-29.

Quoidbach, J., Berry, E. V., Hansenne, M. e Mikolajczak, M. (2010). Positive emotion regulation and well-being: Comparing the impact of eight savoring and dampening strategies. Personality and Individual Differences, 49(5), 368-373. https://doi.org/10.1016/j.paid.2010.03.048

Salovey, P. e Mayer, J. D. (1990). Emotional intelligence. Imagination, Cognition and Personality, 9(3), 185-211. https://doi.org/10.2190/DUGG-P24E-52WK-6CDG

Schneider, T., Lyons, J. e Khazon, S. (2013). Emotional intelligence and resilience. Personality and Individual Differences, 55(8), 909-914. https://doi.org/10.1016/j.paid.2013.07.460

World Health Organization-WHO. (2020). Mental health and psychosocial considerations during the Covid-19 outbreak. WHO.

\section{Financiamento}

Este trabalho é financiado pela FCT - Fundação para a Ciência e a Tecnologia, no âmbito da UIDEF - Unidade de Investigação e Desenvolvimento em Educação e Formação, UIDB/04107/2020. Referência UIDB/04107/2020.

\section{Breve CV dos autores}

\section{Catarina Sobral}

Professora auxiliar convidada do Instituto de Educação da Universidade de Lisboa (IEULisboa), investigadora colaboradora da Unidade de Investigação e Desenvolvimento, Educação e Formação (UIDEF), com doutoramento em Educação na especialidade de formação de professores e mestrado em Ciências da Educação na especialidade de teoria e desenvolvimento curricular, tendo trabalhado como educadora de infância durante onze anos. Interesses de investigação: educação de infância, educação emocional e inclusiva, 
investigação-ação, colaboração, desenvolvimento profissional e mediação socioeducativa. ORCID: https://orcid.org/0000-0003-4017-5481. Email: cmsobral@ie.ulisboa.pt

\section{Ana Paula Caetano}

Professora associada do Instituto de Educação da Universidade de Lisboa (IE-ULisboa), investigadora integrada da Unidade de Investigação e Desenvolvimento, Educação e Formação (UIDEF), com doutoramento e mestrado em Ciências da Educação da Universidade de Lisboa. Coordena o doutoramento em educação, especialidade em educação e supervisão de docentes, e o mestrado em educação e formação: desenvolvimento social e cultural. Investiga temas relacionados com a formação de professores, a cidadania, a educação superior, entre outros. Com publicações nacionais e internacionais em revistas e livros da especialidade, a saber: a formação ética dos docentes, a mediação socioeducativa, a educação intercultural e emocional, a inclusão educativa e a educação artística. ORCID: https://orcid.org/O000-0003-2481-5215. Email: apcaetano@ie.ulisboa.pt 